\title{
Confused Terms in Ordinary Language
}

Greg Frost-Arnold [corresponding author]

Department of Philosophy

Hobart \& William Smith Colleges

300 Pulteney Avenue

Geneva, NY 14456

+1 315.871.8027

gfrost-arnold@hws.edu

James R. Beebe

Department of Philosophy

University at Buffalo

135 Park Hall

Buffalo, NY 14260-4150

jbeebe2@buffalo.edu 


\section{Confused Terms in Ordinary Language}

ABSTRACT: Confused terms appear to signify more than one entity. Carnap (1957) maintained that any putative name that is associated with more than one object in a relevant universe of discourse fails to be a genuine name. Although many philosophers have agreed with Carnap, they have not always agreed among themselves about the truth-values of atomic sentences containing such terms. Some hold that such atomic sentences are always false, and others claim they are always truth-valueless. Field (1973) maintained that confused terms can still refer, albeit partially, and offered a supervaluational account of their semantic properties on which some atomic sentences with confused terms can be true. After outlining many of the most important theoretical considerations for and against various semantic theories for such terms, we report the results of a study designed to investigate which of these accounts best accords with the truth-value judgments of ordinary language users about sentences containing these terms. We found that naïve participants view confused names as capable of successfully referring to one or more objects. Thus, semantic theories that judge them to involve total reference failure do not comport well with patterns of ordinary usage.

Keywords: proper names, empty names, ambiguity, confusion, supervaluation, experimental logic 
I.

A proper name is normally thought of as a word that tags a particular individual. At least, that is what a name is standardly intended to do. We can express this as the Principle of Univocality (PU) (Carnap 1957, 98):

(PU) Every (utterance of a) proper name picks out exactly one entity. (PU) is a claim about the semantics of proper names. Names can also be characterized syntactically or grammatically: all names can be substituted into sentences of the form ' _ _ is $F$ ' to yield grammatical, atomic sentences, and all names can replace quantifiers in grammatical quantified sentences to make another grammatical sentence. ${ }^{1}$ If 'Something is $F$ ' is a grammatical sentence, then so is 'Mars is $F$ '. Of course, a term can meet these purely syntactical or grammatical necessary criteria for namehood, and yet fail to satisfy the principle of univocality. 'Harry Potter' is one such example, since 'Harry Potter is 10 feet tall' is a grammatical sentence of English, yet 'Harry Potter' does not pick out any entity, since Harry Potter does not exist. (One might think Harry Potter does exist, on the grounds that characters in works of fiction exist in some way. The same point can be made using the name 'Vulcan,' which was proposed as the name of a planet between Mercury's orbit and the Sun, to explain discrepancies between observed values and those predicted by Newtonian celestial mechanics.) The proper semantic treatment of names like 'Harry Potter' and 'Vulcan,' which fail to satisfy (PU) because they pick out nothing, has been discussed at length in the philosophy of language literature under the heading of '(the problem of) empty names,'2 and

\footnotetext{
${ }^{1}$ Thanks to an anonymous reviewer for helping us make this formulation more precise.

${ }^{2}$ Cf., e.g., Braun (1993), Reimer (2001), and Everett and Hofweber (2000). For the history of the problem, see Textor (2016). For experimental work on naïve speakers' truth-value judgments of sentences containing non-denoting names, see Piccinini and Scott (2010).
} 
in the logic literature under the heading of 'free logic. ${ }^{3}$ In short: one way (PU) could fail is if an utterance of a name refers to too few individuals (in which case the name is 'empty' or nonreferring).

There is another way that (PU) could fail: a purported name could refer to too many individuals, ${ }^{4}$ i.e., a purported name could fail to refer uniquely. The latter sort of case is less studied in the logic and language literatures. ${ }^{5}$ We could think of such linguistic items as ambiguous or confused names (since one way to be confused is to conflate things, i.e., to take two or more things to be one). As a term of art, we call any linguistic item that grammatically or syntactically behaves like a proper name, yet conflates distinct things, a 'multiply-signifying name.' How well multiple signification captures our pre-theoretic notions of ambiguity and confusion is a question that we do not address here; nonetheless, we hold that multiple signification is one plausible way to model at least some instances of confusion and ambiguity (and in particular, unintentional or unwitting ambiguity, i.e. cases where the speaker lacks the means to discriminate between the multiple meanings).

What semantics should be used for sentences containing multiply-signifying names? One might reasonably hold that a good answer to this question should be constrained by both theoretical arguments and ordinary speakers' usage of such terms. In this paper, we articulate theoretical considerations for and against various possible semantic theories for multiply-signifying names,

\footnotetext{
${ }^{3}$ The phrase 'free logic' abbreviates 'logic free of any existential presuppositions.' In other words, free logics do not assume that every individual constant, i.e. grammatical name, refers to something that exists in the domain of quantification. For overviews of free logic, see Nolt (2010) and Lambert (2001).

${ }^{4}$ As a reviewer pointed out to us, the phrase 'referring to too many things' should not be taken completely literally here. One could reasonably hold that any purported name that is applied to multiple individuals fails to refer entirely, i.e. refers to nothing, on the grounds that all real, genuine reference must uniquely identify an individual. We explore this position below, so we do not want to define it out of existence here. ${ }^{5}$ There are, however, important exceptions, including Field (1973), Lewis (1982), Priest (1995), Millikan (2000), Camp (2002), Lawlor (2007), Frost-Arnold (2008), and Ripley (forthcoming), among others.
} 
and report the results of an empirical study designed to test which of these theories most closely matches ordinary speakers' truth-value intuitions of sentences containing multiply-signifying names. Our results show that the truth-value judgments of naïve participants most closely match semantic theories on which multiply-signifying names can successfully refer to one or more entities and be used to correctly ascribe or deny properties to these entities. More generally, this article is a contribution to the growing sub-field David Ripley has dubbed 'experimental philosophical logic': the "intersection of experimental philosophy and philosophical logic" (2016, 523).

II.

Consider the following story (adapted from Camp 2002, 27):

Fred goes to the pet store and purchases an ant colony in a box. The owner of the pet store tells Fred that every ant colony comes with many small ants but only one big ant. After Fred gets home and begins unpacking his new purchase, he says 'I'm going to call the big ant in this colony 'Charley."' Unbeknownst to Fred, however, there are actually two large ants in this colony. Call them 'Ant A' and 'Ant B.'

In this section, we articulate several possible semantic theories of multiply-signifying names, using the example of 'Charley.' We list some basic pros and cons of each position to flesh out what precisely each position amounts to, to give some sense of the motivations for each position, and to indicate why there is no obviously correct answer to the question of which semantics is the correct one. We keep these considerations relatively brief, because this paper does not aim to render an all-things-considered judgment on which semantics is best. Rather, our goal here is to introduce 
some new data that is arguably relevant to this debate, and to indicate which positions this new data could support and which positions it undercuts.

(1) Neutral semantics. ${ }^{6}$ According to a neutral semantics, every atomic sentence containing a multiply-signifying name, such as 'Charley is an ant,' is neither true nor false. This fits naturally with the view, expressed in (PU), that multiply-signifying names aren't really semantic names at all, since they don't pick out a single individual; and for a lexical item to qualify as a name semantically speaking, it must pick out a single individual. Thus, they are 'defective' or 'corrupt' semantic inputs into sentence schemas, akin to sentence-fragments with missing components, like '___ is happy.' That said, a proponent of neutral semantics could nevertheless maintain that words like 'Charley' are genuine semantic names, but only by accepting violations of the Principle of Univocality. In other words, accepting neutral semantics does not force you to accept that names must refer uniquely.

There are various species of this generic view, distinguished by how non-atomic sentences are assigned truth-values. One differentiation is between the so-called strong Kleene scheme for the logical connectives and the weak Kleene scheme. On the weak Kleene scheme (cf. Table 1), if a sentence has a truth-valueless ${ }^{7}$ component sentence, then the whole sentence is truth-valueless. The strong scheme, in contrast, keeps the classical rules If a conjunction has at least one false conjunct, then the whole conjunction is false, and If a disjunction has at least one true disjunct, then the whole disjunction is true (with the corresponding changes to the material conditional, i.e.

\footnotetext{
${ }^{6}$ The terminology of positive, negative, and neutral semantics is borrowed from the free logic literature (Lehmann 1994). Joseph Camp (2002) defends neutral semantics for all of Fred's sentences containing the word 'Charley.'

${ }^{7}$ We use 'truth-valueless' to abbreviate 'neither true nor false.' This is a slight abuse of terminology, because if there are further truth values in addition to the standard two True and False, then a sentence which has one of those other truth-values is neither true nor false, but is not truth-valueless. This abuse of terminology is harmless for present purposes, since we did not ask subjects about exotic truth-values in our study.
} 
'If $p$ then $q$ ' is logically equivalent to 'Not- $p$ or $q$ '). Our study did not investigate whether speakers' usage follows the strong or weak Kleene scheme, because that distinction has nothing to do with multiply-referring sentences per se-rather, it is about how truth-valueless sentences (of any variety or provenance) interact with conjunction and disjunction.

\begin{tabular}{|c|c|c|c|c|c|c|c|c|c|}
\hline & & \multicolumn{5}{|c|}{ Strong } & \multicolumn{4}{c|}{ Weak } \\
\hline$p$ & $q$ & $p \wedge q$ & $p \vee q$ & $\begin{array}{c}\text { Internal } \\
\sim p\end{array}$ & $\begin{array}{c}\text { External } \\
\sim p\end{array}$ & $p \wedge q$ & $p \vee q$ & $\begin{array}{c}\text { Internal } \\
\sim p\end{array}$ & $\begin{array}{c}\text { External } \\
\sim p\end{array}$ \\
\hline $\mathrm{T}$ & $\mathrm{T}$ & $\mathrm{T}$ & $\mathrm{T}$ & $\mathrm{F}$ & $\mathrm{F}$ & $\mathrm{T}$ & $\mathrm{T}$ & $\mathrm{F}$ & $\mathrm{F}$ \\
\hline $\mathrm{T}$ & $\mathrm{F}$ & $\mathrm{F}$ & $\mathrm{T}$ & $\mathrm{F}$ & $\mathrm{F}$ & $\mathrm{F}$ & $\mathrm{T}$ & $\mathrm{F}$ & $\mathrm{F}$ \\
\hline $\mathrm{T}$ & $\mathrm{N}$ & $\mathrm{N}$ & $\mathbf{T}$ & $\mathrm{F}$ & $\mathrm{F}$ & $\mathrm{N}$ & $\mathrm{N}$ & $\mathrm{F}$ & $\mathrm{F}$ \\
\hline $\mathrm{F}$ & $\mathrm{T}$ & $\mathrm{F}$ & $\mathrm{T}$ & $\mathrm{T}$ & $\mathrm{T}$ & $\mathrm{F}$ & $\mathrm{T}$ & $\mathrm{T}$ & $\mathrm{T}$ \\
\hline $\mathrm{F}$ & $\mathrm{F}$ & $\mathrm{F}$ & $\mathrm{F}$ & $\mathrm{T}$ & $\mathrm{T}$ & $\mathrm{F}$ & $\mathrm{F}$ & $\mathrm{T}$ & $\mathrm{T}$ \\
\hline $\mathrm{F}$ & $\mathrm{N}$ & $\mathbf{F}$ & $\mathrm{N}$ & $\mathrm{T}$ & $\mathrm{T}$ & $\mathrm{N}$ & $\mathrm{N}$ & $\mathrm{T}$ & $\mathrm{T}$ \\
\hline $\mathrm{N}$ & $\mathrm{T}$ & $\mathrm{N}$ & $\mathrm{T}$ & $\mathrm{N}$ & $\mathrm{T}$ & $\mathrm{N}$ & $\mathrm{N}$ & $\mathrm{N}$ & $\mathrm{T}$ \\
\hline $\mathrm{N}$ & $\mathrm{F}$ & $\mathbf{F}$ & $\mathrm{N}$ & $\mathrm{N}$ & $\mathrm{T}$ & $\mathbf{N}$ & $\mathrm{N}$ & $\mathrm{N}$ & $\mathrm{T}$ \\
\hline $\mathrm{N}$ & $\mathrm{N}$ & $\mathrm{N}$ & $\mathrm{N}$ & $\mathrm{N}$ & $\mathrm{T}$ & $\mathrm{N}$ & $\mathrm{N}$ & $\mathrm{N}$ & $\mathrm{T}$ \\
\hline
\end{tabular}

Table 1. The strong and weak Kleene schemes for logical connectives, with internal and external negation. Points of difference between the two schemes are bolded and shaded. 'T,' ' $\mathrm{F}$,' and ' $\mathrm{N}$ ' stand for true, false, and neither true nor false, respectively.

On common versions of both the weak and the strong schemes, the negation of a truthvalueless sentence is again truth-valueless. However, one might instead propose systems in which the negation of a truth-valueless sentence is true, instead of neither true nor false. The motivation for construing negation in this way is that a truth-valueless sentence is in some sense wrong, and thus saying 'Not that wrong thing' is the correct thing to say, and therefore should be true. This form of negation is called 'external' negation (Horn 2001, 125, ch. 6), and is contrasted with 'internal' negation, in which the negation of a truth-valueless sentence is again truth-valueless. In the study described below, we looked to see whether speakers' responses were consistent with a 
neutral semantics combined with internal negation ('neutral internal semantics') or a neutral semantics with external negation ('neutral external semantics'). For example, consider the sentences 'Charley is an ant' and 'Charley is not an ant.' On both neutral proposals, the first sentence is neither true nor false. But the proposals differ over the second sentence: the internal negation proposal makes it neither true nor false, while the external negation proposal makes the second sentence true (since the negation of a truth-valueless sentence is true).

So in all, there are at least four species of the genus of neutral semantics: weak and strong Kleene schemes with internal negation (i.e., the usual Kleene schemes), and weak and strong Kleene schemes with external negation instead. We suspect that no one would actually endorse the combination of weak Kleene and external negation, since it would be odd to hold that a truthvalueless component sentence in a disjunction or conjunction always makes that conjunction or disjunction truth-valueless, but negating a truth-valueless sentence generates a truth-valued sentence. For the weak Kleene scheme seems motivated by the idea that any truth-valueless component always 'spoils' (i.e., makes truth-valueless) the whole sentence, and external negation is incompatible with that idea.

Pros of neutral semantics: (i) A neutral semantics can preserve the principle of univocality (PU), since we need not think of words like 'Charley' as names, semantically speaking-even though, from a syntactic point of view, they play the same role as ordinary names do in forming grammatical sentences. This might be taken to count in favor of these forms of neutral semantics, if one endorses a certain kind of theoretical conservatism that seeks to preserve as many traditional semantic principles as possible. However, as noted above, the proponent of a neutral semantics can also reject (PU) and claim that multiply-signifying names are simply names that either lack semantic values or have non-standard semantic values. Either way, a neutral semantics can allow 
multiply-signifying names within a language. (ii) Each neutral semantics offers a seemingly plausible explanation for why sentences with multiply-signifying names are truth-valueless.

Cons of neutral semantics: (i) On all versions of the view, the expression 'Charley is Charley' will be truth-valueless, but one might feel an intuitive pull toward calling it true. (ii) 'Charley is not Charley' will be either true (on a neutral external semantics), or neither true nor false (on a neutral internal semantics). Intuitively, however, it seems that if 'Charley is not Charley' is going to have a truth-value, it should be false. (iii) Some scholars argue we should avoid truthvalue gaps whenever possible in order to preserve (as much as possible) central tenets of classical logic like the principle of bivalence, which states that every declarative sentence has exactly one truth value, either true or false. All neutral semantics clearly violate this principle (though the weak Kleene scheme violates it more often than the strong one, and adopting internal negation instead of internal will also create the possibility for more violations). (iv) The only neutral position that makes the laws of both excluded middle and non-contradiction true is the combination of the strong Kleene scheme with external negation; all other combinations fail to make one or both true. According to excluded middle, every sentence of the form $p \vee \sim p$ is true. However, if the negation is internal, then both disjuncts are truth-valueless, so the whole sentence is truth-valueless. But if the negation is internal, and the disjunction is weak Kleene, having one truth-valueless disjunct (here, $p$ ) again makes the whole sentence truth-valueless. However, the strong Kleene scheme plus external negation preserves the law of excluded middle: when $p$ is truth-valueless, $\sim p$ will be evaluated as true, and one true disjunct is all one needs on the strong Kleene scheme to make the whole disjunction true. According to the law of non-contradiction, every sentence of the form $\sim(p$ $\wedge \sim p$ ) is true. However, internal negation (regardless of which Kleene scheme one uses) renders $\sim(p \wedge \sim p)$ truth-valueless. External negation would make it true, since $p \wedge \sim p$ is truth-valueless 
when $p$ is truth-valueless, on both the strong and weak Kleene schemes. ${ }^{8}$ (v) Finally, while the strong Kleene scheme combined with external negation preserves the laws of excluded middle and non-contradiction, it still renders $p \wedge \sim p$ neither true nor false (like the other three neutral options), since the conjunction of a truth-valueless $p$ with $\sim p$ (which is true, using external negation) is truthvalueless. Intuitively, however, it seems that any sentence of that form should be false. Thus, the initially plausible explanations provided by the class of neutral semantics seem to bring with them significant theoretical costs.

(2) Negative semantics. On a negative semantics for multiply-signifying names, every atomic sentence containing a multiply-signifying name is false. The restriction to atomic sentences is necessary. Without it, where $b$ is a multiply-signifying name, $F(b)$ and $\sim F(b)$ would both be false. But that is impossible, since the proponent of negative semantics claims that a sentence cannot be both true and false (see (ii) in the next paragraph), and assuming, as all parties to the debate do, that the negation of a falsehood is true. This semantics was proposed and defended for empty names by Tyler Burge (1974), and more recently by Mark Sainsbury (2005), but it can be extended to account for multiply-signifying names as well.

Pros of negative semantics: (i) One motivation for negative semantics over a neutral semantics is simple and straightforward. A sentence with a multiply-signifying name is not true. But a grammatical sentence that is untrue is false. (ii) A second reason favoring negative semantics is more theoretical. Negative semantics restores bivalence, so that truth-value gaps are eliminated. In an important sense, this results in a simpler theory than one that allows the possibility of sentences that are neither true nor false (or both). (iii) As with neutral semantics, a negative

\footnotetext{
${ }^{8}$ Thanks to an anonymous reviewer at $J o L L I$ for correcting a mistake we made regarding these issues in an earlier draft.
} 
semantics can preserve or reject the Principle of Univocality (PU), allowing multiply-signifying names into a language in either case.

Cons of negative semantics: (i) The negative semantics will be committed to counterintuitive claims about the truth-values of various sentences. This includes departures from classical, textbook conceptions of which sentences count as logical truths and which entailment rules count as logically valid. Perhaps the most egregious example is the following: in a negative semantics, sentences of the form $b=b$ are false, when $b$ is multiply-signifying. ${ }^{9}$ Additionally, this means that no identity sentences are logical truths. This latter also holds in neutral semantics, but calling $b=b$ neither true nor false may feel somewhat less repugnant than calling it false. (ii) Negative semantics also has the consequence that the rule of universal instantiation (Everything is $F$, therefore $b$ is $F$ ) is not logically valid. Again, that non-classical feature holds of neutral semantics as well.

(3) Positive semantics. On this view, at least some atomic sentences containing a multiplysignifying name are true. This semantics does not require every sentence with a multiply-signifying name to have a truth-value. The umbrella category of positive semantics encompasses multiple specific semantic proposals.

(3a) Supervaluational semantics. Hartry Field (1973; cf. also Camp 2002, ch. 7) articulated the following account of multiply-signifying names: A sentence $p$ containing a multiply-signifying name is true if $p$ is true on all disambiguations of $p ; p$ is false if $p$ is false on all disambiguations of $p$; and a sentence that is true on some disambiguations and false on others is neither true nor false. So for example, on this semantics, 'Charley is an ant' will be true because each disambiguation of this sentence will be true, since Ant A is an ant, and so is Ant B (and there are

\footnotetext{
${ }^{9}$ For arguments in favor of accepting this apparently counterintuitive consequence, see Burge (1974, IV).
} 
no other disambiguations of 'Charley' besides these two). 'Charley weighs over $100 \mathrm{~kg}$ ' will be false for analogous reasons. However, 'Charley is eating' will be truth-valueless when one of the ants is eating but the other one isn't.

Pros of supervaluational semantics: (i) A supervaluational semantics preserves (PU) to a significant extent, since in each disambiguation of a sentence containing a multiply-signifying name, the name will only signify one entity at a time, and it is the disambiguated sentences that serve as the foundational level of semantic explanation. (ii) A supervaluational semantics also makes many of the intuitively true sentences involving multiply-signifying names true, such as ' $b$ $=b$.' Its verdict that 'Charley is an ant' is true also has some intuitive pull, as does its verdict that 'Charley is over $100 \mathrm{~kg}$ ' is false. (iii) Finally, compared to a neutral semantics, the scope of truthvalueless sentences has shrunk.

Cons of supervaluational semantics: (i) One drawback of a supervaluational semantics, compared to negative semantics, is that, while the supervaluational semantics renders fewer sentences truth-valueless (e.g. 'Charley is an ant'), many sentences remain truth-valueless (e.g. 'Charley is eating now,' when only Ant A is eating). (ii) The supervaluational semantics seems to deliver the wrong verdict about certain statements involving identity. ${ }^{10}$ For on this semantics, 'Charley = Ant A' will be neither true nor false, since it is true on one disambiguation but false on the other. However, intuitively, it seems that we should consider this sentence false. Why? First, and most simply, if 'Charley' refers to anything, it seems to refer to two things, whereas 'Ant A' only refers to one. Thus, the claim that two things are one should be false rather than truthvalueless. Second, if 'Charley = Ant A' is not false, then 'Charley = Ant B' won't be false either

\footnotetext{
${ }^{10}$ The naïve version of supervaluational semantics for multiply-signifying names, found in Field (1973), has this problem. However, this problem can be avoided if one uses a more sophisticated supervaluational semantics, which will be briefly described later in this paragraph.
} 
(by symmetry of reasoning); and (assuming ' $=$ ' is transitive) 'Ant $\mathrm{A}=$ Ant B' is a logical consequence of these two sentences. Yet 'Ant A = Ant B' should definitely come out false, on any remotely plausible semantics. Thus, either 'Charley $=$ Ant A' is false, or logical consequence is not 'backwards-falsehood preserving' (in the terminology of Kremer and Kremer 2003, 227). ${ }^{11}$ (iii) The sentence 'There is nothing identical to Charley' appears intuitively true to some. However, on this simple supervaluational semantics, this sentence is false, since 'There is nothing identical to Ant $A$ ' is false, as is 'There is nothing identical to Ant B.' However, a more sophisticated semantics can be adopted (Frost-Arnold 2008), which makes 'Charley= Ant A' false and ' $\exists x($ Charley $=x)$ ' true, unlike the naïve supervaluationist semantics. ${ }^{12}$

(3b) Contextualist approaches. According to contextualism, if a word type has multiple possible referents, then a particular token use of a word, i.e. an utterance, never refers to more than one thing. Rather, the context of the utterance determines at most one referent for each token of the word. Different versions of contextualist semantics offer different explanations of how contexts accomplish this. One version begins from the causal theory of reference, which holds that a particular noun phrase refers to whatever "thing in the world... gives the best causal explanation of the central features of uses of that word" (Appiah 1996, 63). And if there is no such thing, then the word refers to nothing (e.g., 'unicorn' or 'Santa Claus'). That is, "the referent of each token is the object," Philip Kitcher writes, "figuring appropriately in the explanation of the production of the token," leaving open the possibility that "in some cases, the reference may be genuinely indeterminate" $(1978,527)$. The key point for present purposes is that, for a contextualist, a token

\footnotetext{
${ }^{11}$ An argument is backwards-falsehood preserving iff, whenever the conclusion is false, at least one of the premises is also false.

${ }^{12}$ This is achieved by adding a special rule for atomic formulas containing identity. Specifically, where $a$ and $b$ can be names or variables, if a formula of the form ' $a=b$ ' contains exactly one multiply-signifying name, then ' $a=b$ ' is false.
} 
of a multiply-referring noun-phrase refers to at most one member of the set of possible referents. So, presumably a contextualist will say that some tokens of 'Charley' refer to Ant A, others refer to Ant B, and (at least on Kitcher's view) other tokens are 'genuinely indeterminate.'

As a family of views rather than a specific semantic theory, contextualism (as just characterized) lacks sufficient detail to underwrite very specific predictions. To make such predictions, we would need to know which elements of the context are necessary for determining the referent of a particular token of 'Charley,' as well as the rules governing how these contextual elements combine to determine a truth-value for a sentence containing a confused term. But there are multiple possible ways of spelling this out, none of which is obviously superior to the others. Kitcher's proposal is that “[f]or any given utterance of [a name], one of its modes of reference will be invoked, and that mode will tell us the referent' (McLeish 2005, 671). 'Modes of reference' are ways of establishing reference between a word and an entity; e.g. using a reference-fixing description is one mode of reference, and baptizing a thing you are causally connected to with a name is another. Kitcher further says that the speaker's "dominant intention" to use a particular "mode of reference" is part of the semantically relevant context (Kitcher 1993, 102). Psillos (1997) and McLeish (2005) offer plausible arguments that, in many cases, speakers use noun-phrases without a dominant intention to use one mode of reference over the others.

Pros of contextualist semantics: (i) One prima facie advantage of this proposal is that Fred can utter true sentences containing 'Charley,' even if the traits ascribed are only true of one ant. For example, if Fred is staring directly at Ant A, while that ant is eating a grape, and utters 'Charley is eating a grape' (perhaps pointing as he speaks), then it is at least plausible that that utterance is true (for properly semantic reasons, not merely because of pragmatic mechanisms of speaker's reference, à la Kripke's analysis of Donnellan-style cases (Kripke 1977)). Such a proposal allows 
us to interpret others' utterances more charitably. Of particular importance to Kitcher is that contextualism allows past scientists like Joseph Priestley and Isaac Newton to have stated truths, even when they used vocabulary that current scientists have discarded as defective, thereby reducing discontinuity between the languages. This advantage holds for all the positive semantics to some degree, but contextualism realizes this goal more fully than the other proposals. ${ }^{13}$ (ii) In addition, a contextualist semantics can also preserve the spirit of (PU), inasmuch as each token use of a name will only signify at most a single entity.

Cons of contextualist semantics: One practical problem with contextualist semantics in its current state is that it is not articulated in sufficient detail. This is not a problem with the idea of contextualism itself but rather with its current state of development. We have chosen not to specify it further here, simply because we do not know what the best version of the view is, and we do not want to saddle contextualists with views they would not accept. Concerning Kitcher's particular version of contextualism, Psillos (1997) and McLeish (2005) offer plausible arguments that, in many cases, speakers use noun-phrases without a dominant intention to use one mode of reference for that phrase over the others, and that natural attempts to save Kitcher's view from this problem leads to problems as least as bad.

Another important difficulty is that the contextualist semantics may need to regard Fred's inferences as committing the fallacy of equivocation on a regular basis, which seems rather uncharitable. For suppose that yesterday, Ant A ate only a grape, and Ant B ate only a raisin. Furthermore, imagine Fred saw both of these activities, and utters the following today:
A. 'Charley ate a grape yesterday.'
B. 'Charley ate a raisin yesterday.'

\footnotetext{
${ }^{13}$ Actually, the next proposal (3c) declares more sentences true; however, it does so by declaring many sentences both true and false, a conclusion non-dialethists will find unwelcome.
} 
C. 'Therefore, Charley ate both a raisin and a grape yesterday.'

On a reasonable construal of the contextualist proposal, A and B are both true; in Kitcher's terminology, the mode of reference for the token of 'Charley' appearing in premise A traces back to Ant A, and mutatis mutandis for the 'Charley'-token in premise B. However, C is not true, since there is no ant that ate a raisin and a grape yesterday (if we use Kitcher's framework: there is no mode of reference for 'Charley' that leads back to an ant that ate both foods). On this contextualist interpretation, Fred has committed the fallacy of equivocation. And Fred will do so whenever he makes an inference whose 'Charley'-containing premises do not uniformly refer to one ant or the other. So if we are attempting to follow something like the principle of charity in interpreting Fred's utterances (Kitcher follows Richard Grandy in appealing to what he calls 'the principle of humanity'), there may be a trade-off between charity in attributing truth to sentences and charity in attributing validity to inferences. ${ }^{14}$ Camp makes essentially the same point in (2002, ch. 5).

An astute reviewer pointed out that sentences A and B can both be true (so long as each token of 'Charley' refers to at most one ant) only if the context that makes premise A true is distinct from the context that makes premise B true. However, it is open to a contextualist to say that at least one of A or B is untrue: for example, one could reasonably say that the context of presenting an argument like this one fixes a single context for all three lines. If so, then at least one of the two premises must be untrue (again, so long as each token of 'Charley' refers to no more than one ant), and the logical rule of 'and'-introduction remains valid. Alternatively, following Kitcher, one could also maintain that Fred did not have a dominant intention to use a mode of reference that picked out Ant A when he uttered premise A, and mutatis mutandis for premise B, with the result

\footnotetext{
${ }^{14}$ Psillos (1997) provides critical discussion of Kitcher's contextualist view, which includes a criticism similar to that articulated in this paragraph. McLeish (2006) also criticizes Kitcher's view.
} 
that neither of the two premises are true. ${ }^{15}$ However, both of these ways of saving contextualism from making 'and'-introduction invalid (or making the fallacy of equivocation valid) also face serious problems. If the contextualist says that the two tokens of 'Charley' in the two premises refer to the same ant, then presumably they will need to specify which of the two ants it is-but for reasons of symmetry, neither Ant A nor Ant B appears to be a better candidate than the other for the single referent of the two tokens of 'Charley.' If (perhaps inspired by this symmetry between the two ants) the contextualist instead claims that neither token of 'Charley' refers in the above argument, then contextualism threatens to collapse into negative or neutral semantics. For if Fred can't use 'Charley' to refer (semantically) to Ant A while staring directly at Ant A, then it seems that most, if not all, of Fred's utterances of 'Charley'-tokens won't refer to any ants. ${ }^{16}$

(3c) 'At-least-one' semantics. On this semantics, a sentence $p$ containing a multiplysignifying name will be true if $p$ is true on at least one disambiguation of $p$. There are two subspecies of this view, which differ over the conditions under which $p$ is false. Christina McLeish's view (2006), which she calls "disjunctive partial reference," holds that a confused sentence $p$ is false iff it is false on every disambiguation. This view differs from the one described in David Lewis’s “Logic for Equivocators” (1982), which shares McLeish's characterization of truth, but declares $p$ false if $p$ is false on at least one disambiguation of $p$. Graham Priest (1995) presents the same rule, but while Lewis deals only with the propositional case, Priest expands the view to include first-order logic. ${ }^{17}$ One immediate corollary of this difference between the views of

\footnotetext{
${ }^{15}$ Note that this is a further dimension along which the contextualist position is underspecified: in cases where reference is genuinely indeterminate by the contextualist's lights, does the contextualist adopt a neutral, negative, or positive semantics?

${ }^{16}$ Additionally, as we will see in Table 2 below, our survey participants tended to respond that Fred can utter truths about Ant A using the name 'Charley' while looking at Ant A.

${ }^{17}$ Lewis describes this position as providing an "intuitive interpretation" of the logics RM and LP. Priest specifically adopts LP, which is unsurprising, given that he developed LP and defends it on grounds independent of confused terms.
} 
McLeish and Lewis-Priest is that the Lewis-Priest view allows for confused sentences that are both true and false, whereas McLeish's does not.

Pros of 'at-least-one' semantics: This proposal has the arguably beneficial feature (shared with contextualist semantics) of allowing several sentences containing 'Charley' to express truths, even when the sentence is only true of one of the ants. The Lewis-Priest view also makes sense of the common answer 'Well, yes and no' to an ambiguous question.

Cons of 'at-least-one' semantics: (i) McLeish's view has the consequence that the logical rule of 'and'-introduction is no longer truth-preserving, since it gives the same verdict about the example inference (A. through C.) above as the contextualist semantics: sentence A is true of Ant A (and thus is true simpliciter, on the at-least-one semantics), and sentence B is true of Ant B (and thus true simpliciter), but the sentence $\mathrm{A} \wedge \mathrm{B}$ is not true on any disambiguation. Lewis and Priest's proposal, on the other hand, is truth-preserving: each of the three sentences is both true and false. (ii) Additionally, both McLeish's and Lewis and Priest's semantics commit us to saying that a sentence and its negation can both be true. Consider again sentence A above, 'Charley ate a grape yesterday,' along with its negation, 'Charley did not eat a grape yesterday.' Both of those sentences are true on both semantics. On Lewis and Priest's, each sentence is both true and false; on McLeish's, each is true-only. For McLeish's position, the sting is perhaps lessened somewhat by noting that the conjunction $p \wedge \sim p$ is never true on her semantics—only the individual conjuncts are. ${ }^{18}$ This contrasts with Lewis and Priest's semantics, which allows for instances of $p \wedge \sim p$ that are true (and false at the same time) - though for a paraconsistent logician, this is a feature, not a bug, since it allows them to declare ex falso quodlibet invalid. (iii) On both at-least-one semantics,

\footnotetext{
${ }^{18}$ McLeish (2006, 188-189), the proponent of this semantics, explicitly bites both of these bullets.
} 
modus ponens, modus tollens, and disjunctive syllogism are all invalid. ${ }^{19}$ (iv) On an 'at-least-one' semantics, identity exhibits counter-intuitive behavior. On both versions under consideration, the transitivity of identity fails: 'Ant A = Charley' and 'Charley= Ant B' are both true (and, for Lewis and Priest, also false), but 'Ant $\mathrm{A}=\mathrm{Ant} \mathrm{B}$ ' is untrue. And even stranger, on the Lewis-Priest view, if we allow distinct occurrences of the same name within a sentence to have different disambiguations, 'Charley = Charley' will be both true and false (and thus 'Charley $\neq$ Charley' will be both, as well) (Priest 1995, 365).

The above whirlwind tour of possible semantics for languages containing multiplysignifying names is not intended to be comprehensive or definitive. Rather, it is meant to show that determining which semantics for multiply-signifying names is 'best' is difficult, and that every plausible option comes with downsides. Choosing a semantics will thus involve tradeoffs; one must balance pros and cons.

Our goal in this paper is to investigate the relations between these theories and English speakers' judgments about sentences involving multiply-signifying names. One could be interested in these relationships for at least two reasons. First, one might wonder whether any of the above theories predicts naïve speakers' judgments. Second, one might consider greater conformity to naïve speakers' judgments to be evidence for the superiority of one semantic theory over another. Above, in sketching some of the pros and cons of each semantic proposal, we described certain sentences as 'intuitively' true or 'intuitively' false, and treated a semantics making intuitively true sentences come out true as an advantage for a theory and making intuitively

\footnotetext{
${ }^{19}$ For modus ponens $(p \rightarrow q, p, \therefore q)$ : let $p$ be false on some disambiguations but true on others (and thus true on McLeish's semantics, and both true and false on Lewis-Priest's semantics), and let $q$ be false on all disambiguations (and thus false on both McLeish's and Lewis-Priest's semantics). On this assignment, $p \rightarrow q$ will be evaluated true by McLeish, and both true and false by Lewis-Priest, since there must be at least one disambiguation where $p$ is false. The counterexample for modus tollens is similar.
} 
true sentences come out false as a drawback. Below, we test these claims of intuitive truth and intuitive falsehood against the truth-value judgments of naïve English speakers, to determine whether their judgments line up particularly well with any of the above options. Of course, a philosopher's or logician's theoretical semantics need not match naïve informants' responses precisely_for those responses may well be inconsistent—but many semantic theorizers think that naïve informants' responses do play an important role in theory selection (e.g., Machery et al. 2004, Sytsma \& Livengood 2011, Haukioja 2015, Beebe \& Undercoffer 2016, Ripley 2016).

III.

We recruited 214 undergraduates (average age $=20,55 \%$ female, 61\% Caucasian, $81 \%$ native English speakers) at a large, public university in the northeastern United States to read the story about Fred and his ant colony above and to answer some questions about it. Each participant was given a set of eleven statements to evaluate, ten of which included the name 'Charley.' Before reading the first nine statements, participants were given the following instructions:

For each of the following sentences, please select which of the following options best captures your view of that sentence:
a. True
b. False
c. Both true and false
d. Neither true nor false
e. Don't know/can't tell

All participants then read and responded to the following nine statements:

1. Ant A and Ant B are one and the same ant. 
2. Charley exists.

3. Charley is an ant.

4. Charley is not an ant.

5. Charley is Ant A.

6. Charley is not Ant A.

7. Charley is an elephant.

8. Charley is Charley.

9. Charley is not Charley.

Statement (1) is the only statement in which the name 'Charley' does not appear and was intended to serve as a comprehension check, since the story clearly states that Ant A and Ant B are numerically distinct. For the remaining statements in our study, the name 'Charley' appeared in order to probe participants' intuitions about sentences in which such a multiply-signifying name appears. Statement (2) ascribes existence to something or some things designated by 'Charley.' Statements (3) and (7) ascribe certain properties to whatever (if anything) is picked out by 'Charley,' where one might plausibly think Charley has the property in (3) (viz., being an ant) but lacks the property in (7) (viz., being an elephant). (4) and (6) are the negations of (3) and (5), respectively. Items (8) and (9) were included to determine how respondents viewed logical truths involving multiply-signifying names.

In addition to the nine statements above, each participant was also asked the following question:

10. What does the name 'Charley' refer to?

a. Only one of the large ants

b. Both of the large ants 


\section{c. It doesn't refer to anything}

In contrast to statements (2) through (9), which use the name 'Charley,' question (10) mentions it and asks participants directly for a metalinguistic judgment about the semantic properties of this term. Although the question is metalinguistic, we know from the experimental philosophy literature (cf. Machery et al. 2004, Martí 2009, Machery et al. 2009) that individuals' linguistic judgments about statements in which names are used generally match their metalinguistic judgments about statements in which these names are only mentioned.

Finally, the participant population was divided roughly in half, with each group receiving different bits of additional information and an additional linguistic judgment to make. The first set of participants read the following continuation of the story about Charley: "At the present moment, Ant A is eating, but Ant B is not." These participants were then asked to select one of the five answer choices above (a through e) that best captures their view of the following sentence:

11a. Charley is eating now.

The second set of participants was given the following additional information:

While Fred is looking at his ant colony, Ant A emerges into view. Ant A begins to eat. Ant

B, which is currently hidden from Fred's view, is not eating. At this moment, while looking at Ant A, Fred says 'Charley is eating.'

These participants were then asked the following question:

11b. Did Fred say something true, false, both true and false, or neither true nor false? These participants were asked to select one of the five answer choices (a through e) above.

Statements (11a) and (11b) were included because they involved predicative sentences that focused on the present activity of only one ant. If the term 'Charley' designates a single entity, it designates something that is an ant at all times and an elephant at no times that the entity exists. 
Something similar would be true if 'Charley' designated two entities. But whatever the relation between the term 'Charley' and the ants in Fred's colony, it will not always be true that the ants are eating. And indeed only one of them is eating at the time in question. (11a) and (11b) thus test for individuals' judgments about the semantic properties of 'Charley' in a somewhat different way than the other statements.

The different semantic hypotheses canvassed above assign different values to these eleven statements. A neutral internal semantics classifies statements (2) through (9) and statements (11a) and (11b) as truth-valueless (since on this view, all sentences containing multiply-signifying names are truth-valueless) And the answer to (10) will be either (b) 'Both large ants' or (c) 'It doesn't refer to anything,' since on the neutral semantics, if the name 'Charley' referred to exactly one entity, then 'Charley $=$ Charley' would have to come out true (which it doesn't on the neutral semantics). We see no reason why the negative semantics must favor one of (b) or (c) over the other: if there is a semantic 'slot' or 'hole' that can only generate a true proposition if exactly one object is inserted into it, then both leaving that slot empty and attempting to cram multiple objects into it would result in a defective proposition. ${ }^{20}$ On a neutral external semantics, the negationcontaining statements (4), (6), and (9) will come out true, while the other sentences will remain truth-valueless and the answer to question (10) will remain the same.

\footnotetext{
${ }^{20}$ One might initially think that the neutral semantics cannot say (b) 'Both large ants,' on the grounds that if we have Ant A and Ant B on the left-hand side of the identity-proposition, and Ant A and Ant B on the right-hand side as well, then 'Charley = Charley' would have to be true, contra the neutral semantics. But merely having the same stuff in the two slots of an identity-proposition does not guarantee a true proposition; compare, in standard first-order textbook logic with identity, the schemas ' $P=P$ ' and ' $p=p$ ', where $P$ is any predicate and $p$ is any sentence. These schemas never have true instances, because they are ungrammatical; the neutral-semantics proponent could consider the sentence 'Charley = Charley' ungrammatical, on the grounds that 'Charley' is not a name, or she could consider the sentence to violate semantic rules instead. (This reasoning holds mutatis mutandis for negative semantics, too; see the next paragraph.)
} 
On the negative semantics, the un-negated statements (2), (3), (5), (7), (8), (11a), and (11b) will be false (since on this view all atomic sentences containing multiply-signifying names are false), but the negated statements (4), (6), and (9) will be true. The answer to (10) will be either (b) ('Charley' refers to both ants') or (c) ('neither ant'), for exactly the same reasons (mutatis mutandis) as explained for the neutral semantics in the immediately preceding paragraph.

On a supervaluational semantics, statements (2), (3), and (8) are true (since each disambiguation of these statements is true), and statements (4), (7), and (9) are false (since every disambiguation of them is false). Statements (5), (6), (11a), and (11b) will be neither true nor false (since some disambiguations will be true and some false). And it gives the answer 'Both of the large ants' to question (10) about what the name 'Charley' refers to (in Field's terminology, 'Charley' partially refers to Ant A and partially refers to Ant B).

As discussed above, because the contextualist semantics we are considering is a family of views rather than a particular theory, it does not make predictions that are as specific as the other proposals considered in this paper. On one type of contextualism, because the relevant contextual elements for (2)-(11a) are not fully specified, the answers to each of those questions is either 'Neither true nor false' or 'Don't know/ Can't tell.' On such a view, contextualism's predictions about participant responses will be similar to those of neutral semantics. However, there is another reasonable way for the contextualist to conceive of (2)-(11a). For even if key elements of the context of utterance are underspecified, it may well be that every (reasonable) way of specifying the context will yield the same answer - in which case, the contextualist would give that common answer. The situation is analogous to the open formula ' $x=x^{\prime}$ ': one can think of this formula as lacking a truth-value (because as it stands, $x$ has no determinate value), or as true, because no matter what you plug in for $x$, the resulting sentence will be true (or equivalently, because the 
universal quantification of this sentence is true). Analogously, 'Charley is Charley' will come out as true no matter how the unspecified elements of the context are specified. This latter conception of contextualism is distinct from the neutral semantics, and from the other positive semantics, so it is the one we mean henceforth when we discuss contextualism. On this version of contextualism, statements (2), (3), and (8) will always be true (if each token is used to refer to one of Fred's ants), and statements (4), (7), and (9) are false (if each token is used to refer to one of Fred's ants). Statements (5) and (6) will be true sometimes and false at other times, depending upon which ant the speaker intends to designate by the name 'Charley' on a given occasion; since 'Sometimes true, other times false' is not one of the response options we gave participants, we expect a contextualist would use one of (c), (d), or (most likely) (e) to express this idea. ${ }^{21}$ How the contextualist would answer question (10) is also somewhat tricky; it depends on whether the participant takes the 'Charley' in the question to refer to a token or a type. On any occasion of use, a particular token of 'Charley' will refer to only one ant. However, the name-type can be used to refer to Ant A on some occasions of use and Ant B on others. So, either answer (a) 'Only one of the large ants' or (b) 'Both of the large ants' could seem appropriate. However, answer (c) 'It doesn't refer to anything' is ruled out. According to the contextualist view, the correct answer to (11b) is that Fred said something true when he asserted 'Charley is eating,' since it is clear from

\footnotetext{
${ }^{21}$ Participants might sometimes select 'True' to indicate the thought that it could be true on some occasions that 'Charley' refers to Ant A. Participants could also select 'False,' since it would be false on different occasions. These answers would of course depart from the literal meaning of the answer choices 'True' and 'False,' since on the hypothesized interpretation participants would instead be expressing the idea that (5) 'Could be true' or 'Could be false.' But the puzzling nature of the task could lead some participants to answer in this fashion. For similar reasons, participants might also select 'Both true and false,' since things could go either way, depending on how the context ended up being specified. Or they could say 'Neither true nor false' or 'Don't know/can't tell,' on the grounds that not enough context was provided to determine a truth-value.
} 
the context that he intended to designate Ant A by his use of 'Charley,' and on that occasion Ant A was eating.

The contextualist's answer to (11a) is not straightforward either, for reasons similar to those discussed above for questions (5) and (6). Participants were told only that "At the present moment, Ant A is eating, but Ant B is not" and were then asked if 'Charley is eating now' is true. However, the context in this situation is importantly under-described, since no language user is depicted as producing a token of this sentence in a particular context. So, since some of the relevant contextual features are not specified, 'Both true and false,' 'Neither true nor false' and 'Don't know/can't tell' might well seem to be appropriate contextualist responses to (11a). However, since it is possible for a token of 'Charley' to refer either to the ant that is eating or to the one that is not eating, 'True,' 'False,' or 'Both true and false' might be viewed by participants as appropriate. Nevertheless, in light of the human tendency to charitably fill in contextual details that are missing, we expect contextualist participants to select 'False' and 'Neither true nor false' less often than some of these other possibilities, since these options are less able to render the statement reasonable or sensible.

On both 'at-least-one' semantics, statements (2) and (3) will be (only) true, and statements (4) and (7) will be (only) false. The answer to (10) will be 'Both of the large ants.' Statements (5), (6), (11a), and (11b) will all be true on McLeish's view, but each will be both true and false on the view Lewis presents. If we allow, as Priest does, for multiple occurrences of the same name in a single sentence to be disambiguated differently, then both (8) and (9) will be both true and false. But if we require every occurrence of a name within a sentence to have the same disambiguation, then (8) will be true (only) and (9) will be false (only) on the at-least-one semantics. 
Let us now turn our discussion from the perspective of each semantic theory to the discriminatory power of each question. Statements (5) and (6) tested participants' judgments about the relation between 'Charley' and 'Ant A,' where the latter is an unproblematic referring term. This is relevant to distinguishing between different species of positive semantics. Although the question of what answer participants should provide if the contextualist view correctly models participants' intuitions about multiply-signifying names is unclear, things are different with the supervaluationist and 'at least one' semantics. On the 'unsophisticated' version of supervaluational semantics, which does not give identity statements separate treatment, the answer to (5) and (6) should be 'Neither true nor false,' since neither (5) nor (6) will be true on every disambiguation or false on every disambiguation. On a more sophisticated version of supervaluational semantics, the answer to these questions should be 'False.' On the 'at least one' semantics, participants should select 'Both true and false' for each question if they follow Lewis's proposal, or simply 'True' if they follow McLeish.

Statement (8) provides a direct way to distinguish between the three genera of semantics: neutral semantics declares it neither true nor false, negative semantics declares it false, and positive semantics declares it true (and Priest's at-least-one semantics declares it both true and false). Statement (9) provides a consistency 'check' for subjects who answer (8) in line with the negative or positive semantics (a consistent adherent of the negative semantics will declare (8) false and (9) true, vice versa for a consistent adherent of a positive semantics, with the exception that Priest's semantics make it both true and false), and differentiates between the internal and external notions of negation, for someone who says (8) was truth-valueless. (11a) and (11b) differentiate between the three types of positive semantics. For (11a), the supervaluationist will declare it neither true nor false, the Lewis-Priest 'at-least-one' semantics will declare it both true and false (since it is 
true that Ant $\mathrm{A}$ is eating and false that Ant B is eating), and it will be true (only) for McLeish. As we noted above, it is not completely determined what a contextualist must say about (11a), since some of the details of the production of 'Charley is eating now' are left unspecified. Item (11b) aims to fix this shortcoming, by allowing us to test the contextualist hypothesis more directly. A contextualist would say in (11b) that Fred said something true, whereas in line with (11a), the supervaluationist would declare Fred's utterance to be neither true nor false, and the proponent of the at-least-one semantics would consider Fred's utterance both true and false.

79\% of participants answered Question 1, our comprehension check, correctly. Data from participants who did not answer this question correctly were excluded from subsequent analyses. Responses to the remaining test items from participants who answered Question 1 correctly are summarized in Table 2. The percentages for each cell were shaded according to their magnitude, with those falling between $80 \%$ and $100 \%$ given the darkest shading, those falling between $60 \%$ and $80 \%$ the second darkest, those between $20 \%$ and $40 \%$ the lightest shading, and those between $0 \%$ and $20 \%$ given no shading at all. No cell percentages fell in the middle quintile of possible values between $40 \%$ to $60 \%$. 


\begin{tabular}{|c|c|c|c|c|c|}
\hline \multirow[b]{2}{*}{ Item } & \multicolumn{5}{|c|}{ Participant Answers } \\
\hline & True & False & $\begin{array}{l}\text { Both } \\
\text { T \& F }\end{array}$ & $\begin{array}{l}\text { Neither T } \\
\text { nor F }\end{array}$ & $\begin{array}{l}\text { Don't } \\
\text { Know }\end{array}$ \\
\hline 2. C exists & $75.3 \%$ & $4.2 \%$ & $14.5 \%$ & $3.0 \%$ & $3.0 \%$ \\
\hline 3. $\mathrm{C}$ is an ant & $82.4 \%$ & $3.6 \%$ & $10.3 \%$ & $3.0 \%$ & $0.6 \%$ \\
\hline 4. $C$ is $\sim$ ant & $2.4 \%$ & $81.4 \%$ & $9.6 \%$ & $4.8 \%$ & $1.8 \%$ \\
\hline 5. $C$ is Ant $A$ & $16.2 \%$ & $3.6 \%$ & $22.8 \%$ & $26.3 \%$ & $31.1 \%$ \\
\hline 6. $C$ is $\sim$ Ant $A$ & $2.4 \%$ & $15.2 \%$ & $20.6 \%$ & $32.1 \%$ & $29.7 \%$ \\
\hline 7. $\mathrm{C}$ is elephant & $0.6 \%$ & $86.8 \%$ & $0.6 \%$ & $5.4 \%$ & $6.6 \%$ \\
\hline 8. $\mathrm{C}$ is $\mathrm{C}$ & $76.2 \%$ & $1.2 \%$ & $9.1 \%$ & $9.1 \%$ & $4.3 \%$ \\
\hline 9. $\mathrm{C}$ is $\sim \mathrm{C}$ & $4.9 \%$ & $62.8 \%$ & $15.2 \%$ & $9.1 \%$ & $7.9 \%$ \\
\hline 10. ' $C$ ' refers to? & $\begin{array}{l}62.8 \% \\
(\text { Only 1) } \\
\end{array}$ & $\begin{array}{l}28.0 \% \\
\text { (Both) }\end{array}$ & $\begin{array}{c}9.1 \% \\
\text { (Nothing) } \\
\end{array}$ & $\mathrm{n} / \mathrm{a}$ & $\mathrm{n} / \mathrm{a}$ \\
\hline $\begin{array}{l}\text { 11a. } C \text { is eating } \\
\text { now }\end{array}$ & $20.9 \%$ & $1.2 \%$ & $32.6 \%$ & $18.6 \%$ & $26.7 \%$ \\
\hline $\begin{array}{l}\text { 11b. Did Fred } \\
\text { say something T? }\end{array}$ & $35.1 \%$ & $2.6 \%$ & $33.8 \%$ & $15.6 \%$ & $13.0 \%$ \\
\hline
\end{tabular}

Table 2. Distribution of participant answer choices for items 2 through $11 \mathrm{~b}$, with percentages of participants' answers shaded according to their magnitude.

Chi-squared goodness-of-fit tests were performed on participants' responses to each question in order to see if each distribution of answer choices differed significantly from chance. Each test was significant. ${ }^{22}$ In other words, the distributions of participant answer choices differed significantly from a (flat) distribution in which each answer choice was chosen equally often.

Table 3 summarizes the predictions that each semantic theory makes about the truth value of each test item, with the same shading conventions from Table 2 used to highlight how often each prediction was correct. For instance, in the supervaluational semantics column, the ' $\mathrm{T}$ ' in the row for Question 2 is given the second darkest shading because participants selected this answer between $60 \%$ and $80 \%$ of the time. The ' $\mathrm{T}$ ' for Question 3 in the same column is given the darkest

${ }^{22} \mathrm{Q} 2: \chi^{2}(4, N=166)=324.96, p<.00001 . \mathrm{Q} 3: \chi^{2}(4, N=165)=406.12, p<.00001$. Q4: $\chi^{2}(4, N=167)=$ 397.10, $p$ <00001. Q5: $\chi^{2}(4, N=167)=38.06, p<.00001$. Q6: $\chi^{2}(4, N=165)=47.33, p<.00001$. Q7: $\chi^{2}(4, N=167)=468.60, p<.00001$. Q8: $\chi^{2}(4, N=164)=327.71, p<.00001$. Q9: $\chi^{2}(4, N=164)=192.46$, $p<.00001$. Q10: $\chi^{2}(2, N=164)=72.89, p<.00001$. Q11a: $\chi^{2}(4, N=86)=24.12, p<.0001$. Q11b: $\chi^{2}(4$, $N=77)=30.34, p<.00001$. 
shading because participants selected this answer between $80 \%$ and $100 \%$ of the time. Predictions that were selected between $0 \%$ and $20 \%$ of the time were not shaded at all. And so on.

In the supervaluational column, the cells for statements 5 and 6 are divided in two so that the first rows of the cells can represent the assignments of the naïve supervaluational semantics and the second rows can represent the assignments of the more sophisticated supervaluational view briefly mentioned above. There are no divisions for other statements because the two semantics give the same assignments for them. When cells in the 'At-least-1' column are divided into two rows, the assignments of the Lewis-Priest semantics appear in the first row, and that of Christina McLeish appears in the second. When there are no divisions, the two semantics give the same assignments for the relevant statements. 


\begin{tabular}{|c|c|c|c|c|c|c|c|}
\hline \multirow[b]{3}{*}{ Item } & \multicolumn{7}{|c|}{ Predictions from Semantic Theories } \\
\hline & \multicolumn{3}{|c|}{ Neutral } & \multirow[b]{2}{*}{ Negative } & \multicolumn{3}{|c|}{ Positive } \\
\hline & $\begin{array}{c}\text { Weak } \\
\text { internal }\end{array}$ & $\begin{array}{c}\text { Strong } \\
\text { internal }\end{array}$ & $\begin{array}{c}\text { Strong } \\
\text { external }\end{array}$ & & Superval & Context & $\begin{array}{c}\text { At-least- } \\
1\end{array}$ \\
\hline 2. C exists & $\mathrm{N}$ & $\mathrm{N}$ & $\mathrm{N}$ & $\mathrm{F}$ & $\mathrm{T}$ & $\mathrm{T}$ & $\mathrm{T}$ \\
\hline 3. $\mathrm{C}$ is an ant & $\mathrm{N}$ & $\mathrm{N}$ & $\mathrm{N}$ & $\mathrm{F}$ & $\mathbf{T}$ & $\mathbf{T}$ & $\mathbf{T}$ \\
\hline 4. $\mathrm{C}$ is $\sim$ ant & $\mathrm{N}$ & $\mathrm{N}$ & $\mathrm{T}$ & $\mathrm{T}$ & $\mathbf{F}$ & F & $\mathbf{F}$ \\
\hline \multirow{2}{*}{ 5. $C$ is Ant $A$} & \multirow{2}{*}{$\mathbf{N}$} & \multirow{2}{*}{$\mathbf{N}$} & \multirow{2}{*}{$\mathbf{N}$} & \multirow{2}{*}{$\mathrm{F}$} & $\mathbf{N}$ & \multirow{2}{*}{$\begin{array}{c}\text { Both or } \\
\text { Don't } \\
\text { know }\end{array}$} & Both \\
\hline & & & & & $\mathrm{F}$ & & $\mathrm{T}$ \\
\hline \multirow{2}{*}{ 6. $\mathrm{C}$ is $\sim$ Ant $\mathrm{A}$} & \multirow{2}{*}{$\mathbf{N}$} & \multirow{2}{*}{$\mathbf{N}$} & \multirow{2}{*}{$\mathrm{T}$} & \multirow[b]{2}{*}{$\mathrm{T}$} & $\mathbf{N}$ & \multirow{2}{*}{$\begin{array}{l}\text { Both or } \\
\text { Don't } \\
\text { know }\end{array}$} & Both \\
\hline & & & & & $\mathrm{F}$ & & $\mathrm{F}$ \\
\hline $\begin{array}{l}\text { 7. } \mathrm{C} \text { is } \\
\text { elephant }\end{array}$ & $\mathrm{N}$ & $\mathrm{N}$ & $\mathrm{N}$ & $\mathbf{F}$ & $\mathbf{F}$ & $\mathbf{F}$ & $\mathbf{F}$ \\
\hline 8. $\mathrm{C}$ is $\mathrm{C}$ & $\mathrm{N}$ & $\mathrm{N}$ & $\mathrm{N}$ & $\mathrm{F}$ & $\mathbf{T}$ & $\mathbf{T}$ & $\mathbf{T}^{23}$ \\
\hline 9. $\mathrm{C}$ is $\sim \mathrm{C}$ & $\mathrm{N}$ & $\mathrm{N}$ & $\mathrm{T}$ & $\mathrm{T}$ & F & $\mathbf{F}$ & $\mathbf{F}$ \\
\hline $\begin{array}{l}\text { 10. 'C' refers } \\
\text { to? }\end{array}$ & Nothing & Nothing & Nothing & Nothing & Both & $\begin{array}{c}\text { One or } \\
\text { Both }\end{array}$ & Both \\
\hline $\begin{array}{l}\text { 11a. } C \text { is } \\
\text { eating now }\end{array}$ & $\mathrm{N}$ & $\mathrm{N}$ & $\mathrm{N}$ & $\mathrm{F}$ & $\mathrm{N}$ & $\begin{array}{l}\text { T or } \\
\text { Both }\end{array}$ & $\begin{array}{c}\text { Both } \\
\text { T }\end{array}$ \\
\hline \multirow{2}{*}{$\begin{array}{l}\text { 11b. Fred said } \\
\text { something } \\
\text { T? }\end{array}$} & \multirow[b]{2}{*}{$\mathrm{N}$} & \multirow[b]{2}{*}{$\mathrm{N}$} & \multirow[b]{2}{*}{$\mathrm{N}$} & \multirow[b]{2}{*}{$\mathrm{F}$} & & & Both \\
\hline & & & & & $\mathrm{N}$ & $\mathbf{T}$ & $\mathbf{T}$ \\
\hline Accuracy & $12.4 \%$ & $12.4 \%$ & $9.1 \%$ & $11.1 \%$ & $53.2 \%$ & $68.0 \%$ & $54.8 \%$ \\
\hline Score & & & & & $49.6 \%$ & $56.8 \%$ & $52.8 \%$ \\
\hline
\end{tabular}

Table 3. The semantic values that each semantics would assign to test items 2 through $11 \mathrm{~b}$, with matches between these assignments and participants' responses bolded and shaded.

The last row of Table 3 features an accuracy score for each semantics that was calculated by averaging the percentages of participants who selected the answer choices designated by each theory as correct. For example, because supervaluational semantics says that the correct answers to Questions 2 and 3 are both True, and because 75.3\% of participants selected 'True' for Question

${ }^{23}$ Priest's version, which allows multiple occurrences of the same name to be assigned different disambiguations in the same sentence, makes both 'Charley is Charley' and 'Charley is not Charley' both true and false. 
2 and $82.4 \%$ did so for Question 3,75.3\% and $82.4 \%$ were averaged together with similar percentages from the other nine questions to obtain a rough overall measure of the predictive accuracy of the theory. The naïve version of supervaluational semantics for multiply-signifying names earned an accuracy score of $53.2 \%$, while that of the more sophisticated version was calculated to be $49.6 \%$. Accuracy scores for the contextualist semantics were calculated in two different ways because, as explained above, contextualism sometimes allows for more than one answer choice to be viewed as correct. For example, in response to Question 5, contextualism allows for either 'Both true and false' or 'Don't know/can't tell' to be correct. On the first way of scoring contextualism, the predictive accuracy of contextualism for this question was $53.9 \%$ $(22.8 \%+31.1 \%)$, since $22.8 \%$ of participants selected 'Both true and false' and $31.1 \%$ selected 'Don't know/cant' tell.' However, because this method of scoring might be seen as stacking the deck in favor of contextualism, a second scoring method was employed that included only the average of $22.8 \%$ and $31.1 \%$ in the overall calculation. Using the first method, the accuracy score of contextualism was $68.0 \%$, and on the second it was $56.8 \%$. We believe the first scoring method gives a more accurate picture of the predictive accuracy of contextualism, but we thought it would be helpful to include the second for the sake of comparison.

A chi-squared test of independence was conducted using the various semantic theories as different levels of a single categorical variable and the overall frequency with which each theory made accurate predictions as a second variable. The test was significant, with a robust effect size, meaning that the differences in the accuracy scores between the different theories were both statistically and theoretically significant. ${ }^{24}$ Post-hoc chi-squared tests between the accuracy scores

${ }^{24} \chi^{2}(8, N=16,533)=3,766.03, p<.000000001$, Cramér's $\mathrm{V}=.48 . N$ was obtained in the following fashion: 167 participants who answered the comprehension question correctly x 11 questions answered by each 
of contextualism and the at-least-one semantics reveal a statistically significant difference when the higher, more lenient accuracy score for contextualism is used, ${ }^{25}$ but not when the lower, more restrictive score is used. ${ }^{26} \mathrm{~A}$ post-hoc chi-squared test between the higher accuracy score of contextualism and the accuracy score of the naïve supervaluational account also reveals a statistically significant difference. ${ }^{27}$

The most important characteristic of our data is that the genus of positive semantics matches the truth-value judgments of ordinary language users significantly better than the various neutral or negative semantics, with contextualist and 'at-least-one' semantics edging out supervaluational accounts. These data strongly support the idea that naïve participants think of 'Charley' as referring to one or more entities rather than as failing to refer, and view the thing (or things) denoted by 'Charley’ as existing (Statement 2), falling under the category ANT (Statements 3 and 4), and not counting as (an) elephant(s) (Statement 7). With statements (5) and (6), there was not an answer that a majority of participants preferred to the others, but the three answers 'Both true and false,' 'Neither true nor false,' and 'Don't know/can't tell' were all chosen much more often than 'True' or 'False.' $80.2 \%$ chose one of these answers for statement (5) and the $82.4 \%$ selected one of them for (6). Apparently, they thought that it was neither straightforwardly correct nor straightforwardly incorrect to identify the referent of 'Charley' with Ant A alone. Respondents' answers to (8) and (9) are strongly in line with positive semantics over negative and neutral semantics. Cases like 'Charley $=$ Charley' are used in non-experimental logical research to motivate positive semantics, so our results are not shocking. However, there is one surprising fact

participant x 9 accuracy scores. Accuracy scores for both versions of supervaluationalism were considered and two different accuracy scores for contextualism were entered into the analysis.

${ }^{25} \chi^{2}(1, N=3674)=67.26, p<.000000001$ (uncorrected), Cramér's V $=.14$.

${ }^{26} \chi^{2}(1, N=3674)=1.43, p=.23$ (uncorrected).

${ }^{27} \chi^{2}(1, N=3674)=84.33, p<.000000001$ (uncorrected), Cramér's $\mathrm{V}=.15$. 
about (8) and (9) considered together: (9) is the negation of (8). $80 \%$ of respondents considered (8) true, but only $60 \%$ considered (9) false. So $20 \%$ of respondents thought the negation of a true sentence need not be false. In every account of negation with which we are familiar, the negation of a true sentence must be false.

In response to Question (10), almost two thirds of participants judged that 'Charley' refers to only one of the large ants, while almost one third thought that the name referred to both. Relatively few thought that the term failed to refer to anything. Their responses to this question favor the contextualist semantics over the other two positive approaches.

On questions (11a) and (11b), the answer choice 'Both true and false' was selected more often than on other questions. This might initially appear to be in tension with the fact that more than half of participants responded to (10) by saying that 'Charley' refers to only one of the large ants. For if 'Charley' only refers to one ant, then it would not make sense to say (11a) that 'Charley is eating' is both true and false when one ant is eating but the other isn't — rationally holding that sentence to be both true and false intuitively requires that Charley refer to multiple ants: one who is eating, and one who is not. Looking at the data in this way, it seems participants are of two minds: if we look at participant replies to (10), then 'Charley' has one referent; but participant replies to (11a-b) indirectly suggest that 'Charley' refers to both ants.

This apparent tension is lessened somewhat if we disaggregate participant responses by answer to (10), as shown in Table 4. Participants who said that 'Charley' refers to just one ant were not very likely (17\%) to hold that 'Charley is eating' is both true and false when one ant is eating and the other isn't (11a), whereas participants who held that 'Charley' refers to both Ant A and Ant B were very likely (69\%) to say that 'Charley is eating' is both true and false. A similar pattern, though less pronounced (26\%-57\%), appears for (11b). So while the aggregate data 
initially appears to suggest that a majority of participants hold a prima facie contradictory view (namely, 'Charley' refers both to just one ant, and to both ants), this initial appearance is mitigated when we see that the people who say on question (10) that 'Charley' only refers to one ant tend to give the answer one would expect from someone with that belief for question (11a-b), not the answer we would expect from someone who believes 'Charley' refers to two ants. However, it is worth noting that there is a non-trivial subset of participants who do hold the prima facie contradictory position. ${ }^{28}$

\begin{tabular}{|c|c|c|c|c|c|c|c|c|c|c|}
\hline & \multicolumn{4}{|c|}{ Question 11a } & \multicolumn{4}{c|}{ Question 11b } \\
\hline $\begin{array}{c}\text { Question } \\
\text { 10 }\end{array}$ & True & False & Both & Neither & $\begin{array}{c}\text { Don't } \\
\text { Know }\end{array}$ & True & False & Both & Neither & $\begin{array}{c}\text { Don't } \\
\text { Know }\end{array}$ \\
\hline Only 1 & $21 \%$ & $2 \%$ & $17 \%$ & $23 \%$ & $38 \%$ & $40 \%$ & $0 \%$ & $26 \%$ & $19 \%$ & $14 \%$ \\
\hline Both & $21 \%$ & $3 \%$ & $69 \%$ & $8 \%$ & $0 \%$ & $30 \%$ & $4 \%$ & $57 \%$ & $0 \%$ & $9 \%$ \\
\hline None & $0 \%$ & $8 \%$ & $25 \%$ & $33 \%$ & $33 \%$ & $18 \%$ & $18 \%$ & $27 \%$ & $18 \%$ & $18 \%$ \\
\hline
\end{tabular}

Table 4. Distributions of participant answer choices for Question 10, broken down in subcategories of answers to Question 11a and 11b, with percentages shaded according to their magnitude.

IV.

Our findings strongly suggest that naïve English speakers' truth-value judgments are better modeled by positive semantics than by negative or neutral semantics. For six of the eleven questions that we asked participants $(2,3,4,7,8,9)$, all three species of positive semantics made the same prediction. In each of these six cases, the positive-semantics prediction was chosen by a majority of the participants. The negative-semantics prediction matched the majority answer in only one of these six cases, and the neutral-semantics prediction matched in none of them.

\footnotetext{
${ }^{28}$ We thank an anonymous $J o L L I$ referee for preventing us from drawing a stronger conclusion from this data than was warranted.
} 
For the four questions $(5,6,11 \mathrm{a}, 11 \mathrm{~b})$ that did not generate solid agreement from participants on any single answer, the predictions of negative semantics did worse than those of neutral or positive semantics. For none of these questions was the prediction of negative semantics chosen even $20 \%$ of the time.

Within the class of positive semantics, the supervaluational approach fared somewhat worse than the contextualist and at-least-one approaches. Almost no subjects chose the sophisticated supervaluationist predictions to Questions 5 and 6. For Question 10, only the contextualist semantics predicted the majority response. And for Questions 11a and 11b, contextualist and 'at-least-one' semantics outperformed supervaluationism. Because only contextualist semantics predicted the majority response for Q10 and because the predictions of the at-least-one semantics did not outperform those of contextualist semantics, the contextualist semantics was the best overall.

How broadly do our findings generalize? As a reviewer has pointed out, a non-unique reference-fixing description is not the only way a word can come to conflate distinct entities. Multiple groundings (Devitt 1981, 150), where the different grounding-events refer to two distinct things with the same name, could achieve similar effects. For example, suppose Fred mistakenly believes there is only one ant in his colony, but does not utter a reference-fixing description. Further suppose that Ant A is only visible during the morning, and Ant B is only visible in the evenings, so that Fred sees each one roughly half the time. Finally, suppose that Fred refers to whatever big ant he sees as 'Charley.' It is plausible, though not guaranteed, that the name 'Charley' in these circumstances would be semantically identical to 'Charley' in the original, reference-fixing story. Our experimental results may transfer over to other cases such as equally- 
balanced multiple groundings, but our data were restricted to the case of non-unique referencefixing descriptions.

Finally, while we do not believe that there is an overly simple and direct relation between the truth-value judgments of naïve participants and the correctness of various semantic theories, we nevertheless do believe that comparing semantic theories to patterns of ordinary usage can be valuable, insofar as ordinary usage is widely taken to be one kind of constraint on semantic theorizing. Though not everyone agrees on the extent to which greater conformity to naïve judgments should count in favor of one semantic theory over another, we offer our findings as one kind of consideration for theorists to take into account when constructing explanations of multiplysignifying names. 


\section{References}

Appiah, Kwame Anthony. 1996. "Race, Culture, Identity: Misunderstood Connections." The Tanner Lectures on Human Values 17: 51-136.

Beebe, James R., and Ryan J. Undercoffer. 2016. "Individual and Cross-Cultural Differences in Semantic Intuitions: New Experimental Findings.” Journal of Cognition and Culture 16: $322-57$.

Braun, David. 1993. "Empty Names.” Noûs 27: 449-469.

Burge, Tyler. 1974. "Truth and Singular Terms.” Noûs 8: 309-25.

Camp, Joseph. 2002. Confusion. Cambridge, MA: Harvard University Press.

Carnap, Rudolf. 1956. Meaning and Necessity. 2nd edition. Chicago: University of Chicago Press.

Devitt, Michael. 1981. Designation. New York: Columbia University Press.

Everett, Anthony and Thomas Hofweber (eds.). 2000. Empty Names, Fiction, and the Puzzle of Non-Existence. Stanford, CA: CSLI.

Field, Hartry. 1973. “Theory Change and Indeterminacy of Reference.” Journal of Philosophy 70: $462-81$.

Frost-Arnold, Greg. 2008. "Too Much Reference: Semantics for Multiply Signifying Terms." Journal of Philosophical Logic 37: 239-57.

Haukioja, Jussi (ed.). 2015. Advances in Experimental Philosophy of Language. London: Bloomsbury.

Horn, Laurence. 2001. A Natural History of Negation. CSLI Publications.

Kitcher, Philip. 1978. "Theories, Theorists and Theoretical Change." Philosophical Review 87: $519-547$.

Kitcher, Philip. 1993. The Advancement of Science. New York: Oxford University Press. 
Kremer, Philip and Michael Kremer. 2003. "Some Supervaluation-Based Consequence Relations," Journal of Philosophical Logic 32: 225-244.

Kripke, Saul. 1977. "Speaker Reference and Semantic Reference," in French, Uehling, and Wettstein (eds.), Contemporary Perspectives in the Philosophy of Language, Minneapolis: University of Minnesota Press, 6-27.

Lambert, Karl. 2001. "Free Logics." In Lou Goble (ed.), The Blackwell Guide to Philosophical Logic. Blackwell, 258-79.

Lawlor, Krista. 2007. “A Notional Worlds Approach to Confusion.” Mind and Language 22: 150172.

Lehmann, Scott. 1994. "Strict Fregean Free Logic.” Journal of Philosophical Logic 23: 307-36.

Lewis, David. 1982. "Logic for Equivocators.” Nô̂s 16: 431-41.

Machery, Edouard, Ron Mallon, Shaun Nichols, and Stephen Stich. 2004. "Semantics, CrossCultural Style.” Cognition 92: B1-B12.

Machery, Edouard, Christopher Y. Olivola, and Molly De Blanc. 2009. "Linguistic and Metalinguistic Intuitions in the Philosophy of Language.” Analysis, 69, 689-94.

Martí, Genoveva. 2009. “Against Semantic Multi-Culturalism.” Analysis 69: 42-8.

McLeish, Christina. 2005. “Scientific Realism Bit by Bit: Part I. Kitcher on Reference.” Studies in History and Philosophy of Science Part A 36: 667-685.

McLeish, Christina. 2006. "Realism Bit by Bit: Part II. Partial Disjunctive Reference." Studies in History and Philosophy of Science Part A 37: 171-90.

Millikan, Ruth. 2000. On Clear and Confused Ideas. Cambridge University Press.

Nolt, John. 2010. "Free Logic.” In Edward Zalta (ed.), Stanford Encyclopedia of Philosophy. Available at: https://plato.stanford.edu/entries/logic-free/. 
Piccinini, Gualtiero, and Sam Scott. 2010. "Recovering What Is Said with Empty Names." Canadian Journal of Philosophy 40: 239-273.

Pietroski, Paul, Jeffrey Lidz, Tim Hunter, and Justin Halberda. 2009. “The Meaning of 'Most': Semantics, Numerosity and Psychology." Mind \& Language 24:554-85.

Priest, Graham. 1995. "Multiple Denotation, Ambiguity, and the Strange Case of the Missing Amoeba." Logique \& Analyse 150-152: 361-373.

Psillos, Stathis. 1997. "Kitcher on Reference." International Studies in the Philosophy of Science 11: $259-72$.

Reimer, Marga. 2001. "The Problem of Empty Names." Australasian Journal of Philosophy 79: 491-506.

Ripley, David. 2016. "Experimental Philosophical Logic.” In Justin Sytsma and Wesley Buckwalter (eds.), A Companion to Experimental Philosophy. Wiley, 523-34.

Ripley, David. forthcoming. "Blurring: An Approach to Conflation." Notre Dame Journal of Philosophical Logic.

Sainsbury, Mark. 2005. Reference Without Referents. New York: Oxford University Press.

Sytsma, Justin, and Jonathan Livengood. 2011. “A New Perspective Concerning Experiments on Semantic Intuitions.” Australasian Journal of Philosophy. 89: 315-32.

Textor, Mark. 2016. "Vacuous Names in Early Analytic Philosophy." Philosophy Compass 11: 316-326. 